\title{
Antihypertensive, antidyslipidemic and endothelial modulating activities of Orchis mascula
}

\author{
Nauman Aziz ${ }^{1,2}$, Malik Hassan Mehmood ${ }^{1,2}$, Hasan Salman Siddiqi ${ }^{1,2}$, Saf-ur-Rehman Mandukhail ${ }^{1,3}$, \\ Fatima Sadiq ${ }^{1}$, Wajiha Maan ${ }^{1}$ and Anwarul Hassan Gilani ${ }^{1}$
}

The objective of this study was to investigate the possible mode(s) of action for the medicinal use of Orchis mascula (OM) (family Orchidaceae) in hypertension and dyslipidemia. In spontaneously hypertensive rats (SHRs), OM significantly $(P<0.05)$ reduced systolic blood pressure to $174.2 \pm 9.63$ vs. $203.4 \pm 7.13 \mathrm{~mm} \mathrm{Hg}$ (mean \pm s.e.m.; $n=7-10$ ) and improved endothelial dysfunction by increasing acetylcholine-induced relaxation. In normotensive anesthetized rats, the crude extract of $\mathrm{OM}(\mathrm{Om} . \mathrm{Cr})$ at 10 and $30 \mathrm{mg} \mathrm{kg}^{-1}$ caused a dose-dependent attenuation of mean arterial pressure. $\mathrm{OM}$ also decreased serum triglycerides to $29.28 \pm 6.99$ vs. $93.84 \pm 5.7 \mathrm{mg}$ per $100 \mathrm{ml}(P<0.001)$, low-density lipoprotein-cholesterol to $5.99 \pm 1.27 \mathrm{vs.} 21.9 \pm 3.5 \mathrm{mg}$ per $100 \mathrm{ml}(P<0.05)$ and atherogenic index to $0.096 \pm 0.017$ vs. $0.36 \pm 0.08 \mathrm{mg}$ per $100 \mathrm{ml}(P<0.05)$. OM significantly reduced lipid levels in tyloxapol and high fat diet-induced hyperlipidemia. In a second model, OM also reduced gain in body weight with a reduction in daily diet consumption. In isolated rabbit aorta, $\mathrm{Om}$.Cr caused concentration-dependent relaxation of both phenylephrine and high $\mathrm{K}^{+}(80 \mathrm{~mm})$-induced contractions and a rightward shift of the calcium concentration-response curves similar to the effect seen with verapamil. In conclusion, OM shows antihypertensive and endothelial-modulating effects mediated through multiple pathways that include direct vasodilation by calcium channel blockade and reduction of plasma lipids by inhibition of biosynthesis, absorption and secretion. This study rationalizes the medicinal use of OM in hypertension and dyslipidemia. However, further studies are required to identify the active constituents of this plant.

Hypertension Research (2009) 32, 997-1003; doi:10.1038/hr.2009.148; published online 11 September 2009

Keywords: antidyslipidemic; antihypertensive; calcium antagonist; endothelial dysfunction; Orchis mascula

\section{INTRODUCTION}

Orchis mascula (OM) Linn. (syn. Orchis latifolia Linn., Dactylorhiza gagariana Soo), locally known as Saalab misri, belongs to the family Orchidaceae. It is found in most parts of Europe and North Africa, as well as in Western and Northern Asia. Iran and Afghanistan are the major commercial sources of the plant. Its roots are used for medicinal purposes. In folk medicine of Pakistan and India, it is prescribed individually or along with other herbs for nervous and muscular, as well as sexual dysfunction and cardiovascular diseases (CVDs). It is also effective in alleviating diarrhea, dysentery and chronic inflammation. ${ }^{1}$

The most important constituent of $\mathrm{OM}$ is mucilage, comprising $48 \%$ of the plant by mass. OM also contains $1 \%$ sugar, $2.7 \%$ starch, $5 \%$ nitrogenous substance and, when fresh, a trace of volatile oil. It yields $2 \%$ ash, consisting chiefly of phosphates and chlorides of potassium and calcium. Recently, we reported the antihypertensive, antioxidant, antidyslipidemic and endothelial-modulating activities of a polyherbal formulation (POL-10) that contained OM as one of the ingredients. ${ }^{2}$ However, there are no reports in the literature regarding the biological activity of this plant alone. Therefore, the aim of this study was to investigate the cardiovascular effects of OM in different animal models to rationalize its medicinal use in hypertension and dyslipidemia.

\section{METHODS}

Plant material and extraction

Orchis mascula roots were purchased from a local herbal store in Karachi, Pakistan, and were authenticated by Mr M. Afzal Rizvi, a botanist at the Hamdard University (Karachi). The sample was deposited in the herbarium of the Natural Products Research Division in the Department of Biological and Biomedical Sciences (Aga Khan University, Karachi, Pakistan) with voucher number OM-RT-03-06-70. The roots were ground into fine powder. For the chronic study, OM powder was mixed with diet ad libitum. However, for phytochemical and in vitro studies, OM powder was soaked in $70 \%$ aqueous methanol for 3 days with occasional shaking. It was filtered through a muslin cloth and then through a Whatman qualitative grade 1 filter paper. ${ }^{3}$ This procedure was repeated three times and the combined filtrate was evaporated using a rotary evaporator at $35-40{ }^{\circ} \mathrm{C}$ under reduced pressure of $-760 \mathrm{~mm} \mathrm{Hg}$ to obtain a thick, dark brown, crude extract of OM (Om.Cr), with a yield of $\sim 15.9 \%(\mathrm{w} / \mathrm{w})$.

${ }^{1}$ Natural Product Research Division, Department of Biological and Biomedical Sciences, The Aga Khan University Medical College, Karachi, Pakistan; ${ }^{2}$ Department of Pharmacology, Faculty of Pharmacy, University of Karachi, Karachi, Pakistan and ${ }^{3}$ Department of Pharmacy, University of Balochistan, Quetta, Pakistan Correspondence: Dr AH Gilani, Department of Biological and Biomedical Sciences, The Aga Khan University Medical College, Karachi-74800, Pakistan. E-mail: anwar.gilani@aku.edu

Received 7 April 2009; revised 27 July 2009; accepted 30 July 2009; published online 11 September 2009 


\section{Drugs and standards}

Acetylcholine chloride, cholesterol, cholic acid, phenylephrine (PE), phentolamine hydrochloride, norepinephrine, verapamil hydrochloride, potassium chloride and tyloxapol reagent grade were purchased from Sigma Aldrich Chemical Company (St Louis, MO, USA), whereas calcium chloride, glucose, magnesium chloride, magnesium sulfate, potassium dihydrogen phosphate, sodium bicarbonate, sodium chloride and sodium dihydrogen phosphate and methanol used for extraction were purchased from E. Merck KGaA (Darmstadt, Germany). Randox diagnostic kits for serum analyses were purchased from Randox Laboratories (Antrim, UK). Butter fat was purchased from United Bakers (Karachi, Pakistan). All chemicals used were of the highest purity grade. Physiological salt solutions were prepared fresh in distilled water on the day of each experiment, whereas stock solutions of all the drugs and extract were prepared in distilled water or saline and the dilutions were prepared fresh on the day of each experiment.

\section{Animals}

Spontaneously hypertensive rats (strain: SHR/NCrlBR; hypertensive, nonstroke) and their normotensive controls, Wistar Koyoto (WKY) rats, were imported from the Animal Resource Centre (Australia), at the age of 4 weeks and experiments were started at 20-24 weeks of age. Other animals, such as Sprague-Dawley (SD) rats (170-200 g) and rabbits (1.5-2 kg) of either sex, were sourced locally and housed at the animal house of Aga Khan University. Animals were kept in plastic cages $\left(47 \times 34 \times 18 \mathrm{~cm}^{3}\right)$ with sawdust (changed every $48 \mathrm{~h}$ ) and were maintained at $23-25^{\circ} \mathrm{C}$ with free access to food and water. Rabbits $(1-1.2 \mathrm{~kg}$ ) were starved for $24 \mathrm{~h}$ before the experiment and killed by cervical dislocation. All experiments complied with the rulings of the Institute of Laboratory Animal Resources, Commission on Life Sciences, National Research Council ${ }^{4}$ and were approved by the Ethics Committee of the Aga Khan University (Karachi, Pakistan).

\section{Phytochemical screening}

The crude extract was screened for the presence of saponins, flavonoids, tannins, phenols, coumarins, sterols, terpenes, alkaloids and anthraquinones using methods described previously by Tona et al. ${ }^{5}$

\section{Preparation of diets}

The following four types of diet were prepared:

a. Normal diet: The normal diet was prepared as described previously by Harkness and Wagner ${ }^{6}$ at the animal house of the Aga Khan University, Karachi. The standard diet consisted of flour $(5 \mathrm{~kg})$, chokar $(5 \mathrm{~kg})$, molasses $(150 \mathrm{~g})$, salt $(75 \mathrm{~g})$, nutrivet-L $(33 \mathrm{~g})$, potassium metabisulfite $(15 \mathrm{~g})$, oil $(500 \mathrm{~g})$, fishmeal $(2.25 \mathrm{~kg})$ and powdered milk $(2 \mathrm{~kg})$, comprising a total mass of $\sim 13 \mathrm{~kg}$ of food material.

b. Normal diet with OM: OM powder was mixed with the normal diet in $3 \% \mathrm{w} / \mathrm{w}$.

c. Atherogenic diet: Cholesterol $(2 \% \mathrm{w} / \mathrm{w})$, cholic acid $(0.5 \% \mathrm{w} / \mathrm{w})$ and butter fat $(5 \% \mathrm{w} / \mathrm{w})$ were added to the normal diet, as described by Ichihashi et al. ${ }^{7}$ with slight modifications.

d. Atherogenic diet with OM: OM $(3 \% \mathrm{w} / \mathrm{w})$ was mixed in $\operatorname{diet} \mathrm{C}$.

All measures were taken to ensure the uniform mixing of additives and OM powder in dry ingredients of the diet before kneading.

\section{Pharmacological parameters}

Assessment of antihypertensive activity. For the assessment of antihypertensive activity, SHRs were used in the protocol reported by Rodrigo et al. ${ }^{8}$ with slight modifications. Male SHRs aged 20-24 weeks were randomly divided into 2 groups ( $n=7$ each). For 8 weeks, group 1 was fed diet A (normal diet) and group 2 was fed diet B (normal diet plus OM). WKY rats served as normotensive controls and were fed diet A for the same period. Systolic blood pressure (BP) levels of SHRs were estimated daily using a tail-cuff plethysmograph (Model 92, IITC, Woodland Hills, CA, USA) coupled to a PowerLab 4/25 data acquisition system before and during the 8 weeks of treatment. After acclimatization with the BP measurement procedure, 3-8 readings of systolic BP of each conscious animal (with 5-10 min intervals) were recorded, and mean values were calculated after values with large variations were discarded. Systolic BP was measured at 0,4 and 8 weeks of treatment. All experimental variables such as temperature $\left(27^{\circ} \mathrm{C}\right)$, respiratory and body movements, as well as noise levels were minimized to ensure the best possible quality of data. The described noninvasive BP measurement is reported to have $96 \%$ correlation with direct BP (which leads to a variation of $\pm 10 \mathrm{~mm} \mathrm{Hg}$ ) ${ }^{8}$ and was recorded using a computer running Chart 5.3 software (ADInstruments, Sydney, Australia). Heart rate was calculated electronically using the cyclic measurements option of the Chart software. Ten days before the beginning of the experiment, rats were trained by exposing them daily to measurement condition for $1-2 \mathrm{~h}$.

Blood pressure was also monitored invasively as described previously. ${ }^{9}$ Adult rats (180-200 g) of either sex were used. The animals were anesthetized with an intraperitoneal (i.p.) injection of sodium thiopental (Pentothal, $70-90 \mathrm{mg} \mathrm{kg}^{-1}$ body weight), and arterial BP was recorded through carotid artery cannulation by a pressure transducer (MLT1199) coupled to a Bridge Amplifier and PowerLab 4/25 (ADInstruments). Drugs were injected through a cannula inserted into the jugular vein. After a 20 -min period of equilibration equilibrium, the rats were injected intravenously with $0.1 \mathrm{ml}$ saline $(0.9 \% \mathrm{NaCl})$ or with the same volume of test substance. Arterial pressure was allowed to return to the resting level between injections. Control responses of standards, such as acetylcholine (ACh, $1 \mathrm{mg} \mathrm{kg}^{-1}$ ) and norepinephrine $\left(1 \mathrm{mg} \mathrm{kg}^{-1}\right.$ ), were obtained before the extracts were tested. Changes in mean arterial pressure (MAP) were recognized as the difference between the steady-state value before and the lowest reading after injection. MAP was calculated as the sum of the diastolic pressure (DP) and one-third of the pulse pressure (PP), where $\mathrm{PP}=\mathrm{SP}-\mathrm{DP}$ $(\mathrm{SP}=$ systolic pressure).

Measurement of vascular reactivity in isolated rat aorta. At the end of the treatment, SHR and WKY rats were fasted for $16 \mathrm{~h}$ and anesthetized with diethyl ether by inhalation. Blood was collected through cardiac puncture and serum was analyzed for lipid profile and glucose level. Thoracic aortae were isolated and studied for endothelial reactivity.

The procedure described by Furchgott and Zawadski ${ }^{10}$ was followed with some modifications. The descending thoracic aortae were transferred immediately into Kreb's bicarbonate buffer (composition in mM: NaCl: 118.4, $\mathrm{KCl}: 4.7, \mathrm{CaCl}_{2}: 2.5, \mathrm{KH}_{2} \mathrm{PO}_{4}: 1.2, \mathrm{MgSO}_{4}: 1.2, \mathrm{NaHCO}_{3}: 25$ and glucose: 11 ), cleaned of periadventitial tissue and cut transversally into ring segments ( $3 \mathrm{~mm}$ in length). Each ring was placed in a tissue bath filled with Kreb's buffer $\left(37^{\circ} \mathrm{C}\right)$, bubbled with carbogen $\left(95 \% \mathrm{O}_{2}\right.$ and $\left.5 \% \mathrm{CO}_{2}\right)$ and attached to a force transducer (model FORT100) coupled to a Transbridge (model TBM4M, World Precision Instruments, Hertfordshire, UK) and a PowerLab data acquisition system (model ML845, ADInstruments) and a computer running the Chart software (version 5.3) for measuring isometric tension. Rings were allowed to equilibrate for 60-90 min at a resting tension of $2 \mathrm{~g}$ with changes of buffer every $15 \mathrm{~min}$. When the isometric tension had stabilized, inhibitory concentration-response curves (CRCs) of ACh $\left(1 \times 10^{-9}-10^{-5} \mathrm{M}\right)$ were constructed against contractions induced with a submaximal dose of $\mathrm{PE}$ $\left(1 \times 10^{-6} \mathrm{M}\right)$.

Assessment of vasodilator and inhibition of calcium channels and calcium release activity in rabbit aortae. Direct vasodilator activity and its possible mode of action were studied using isolated rabbit aortae as described by Gilani et al. ${ }^{9}$ For the in vitro study, we preferred to use rabbits that are commonly used in our laboratory for different purposes, thus using multiple tissues from the same animals to maximize ethical and economical utilization. Rabbits were killed by cervical dislocation. The descending thoracic aortae were removed, cut into 2$3 \mathrm{~mm}$ wide rings and set up in a $5 \mathrm{ml}$ tissue bath as described previously. After an equilibrium period of $1 \mathrm{~h}$, the tissues were stabilized with a fixed dose of PE $(1 \mu \mathrm{M})$. The tissues were considered stable only when similar responses were obtained from repeated doses of PE, which usually took 60-90 min. Vasoconstricting effects of the extract were first determined on the resting baseline of the tissue. The extract was later tested for its ability to relax the contractions induced with PE $(1 \mu \mathrm{M})$ and high $\mathrm{K}^{+}(80 \mathrm{~mm})$. To confirm the calcium channel blocking (CCB) activity, $\mathrm{Ca}^{2+} \mathrm{CRCs}$ were constructed in a $\mathrm{Ca}^{2+}$-free medium. Subsequently, the effect of increasing dose of the extract was determined on the $\mathrm{Ca}^{2+}$ CRCs. A shift in the $\mathrm{Ca}^{2+}$ curves to the right would have confirmed CCB 
activity. To determine whether the extract was also inhibiting the $\mathrm{Ca}^{2+}$ release from intracellular stores or blocking the calcium influx across the cell membrane (through the voltage-dependent or receptor-operated channels), the effect of increasing extract dose was observed on PE $(1 \mu \mathrm{M})$ peaks in $\mathrm{Ca}^{2+}$ normal and in $\mathrm{Ca}^{2+}$-free Kreb's solution, with $\mathrm{Ca}^{2+}$ omitted and EDTA (ethylenediaminetetraacetic acid) $(0.1 \mathrm{~mm})$ added to ensure total elimination of extracellular $\mathrm{Ca}^{2+}$ without harmful effects on $\mathrm{Ca}^{2+}$ inside the cell. ${ }^{11}$

Effect on tyloxapol-induced hyperlipidemia. The tyloxapol-induced hyperlipidemic model ${ }^{12}$ was followed with slight modifications. Male SD rats weighing $160-180 \mathrm{~g}$ were randomly divided into three groups ( $n=6$ each). Groups 1 and 2 were fed diet A (normal diet) and group 3 was fed diet B (normal diet with OM). After 10 days of the treatment, all animals were fasted for $7 \mathrm{~h}$ and group 1 received saline $\left(10 \mathrm{ml} \mathrm{kg}^{-1}\right.$; i.p.) whereas groups 2 and 3 were administered tyloxapol $\left(500 \mathrm{mg} \mathrm{kg}^{-1}\right.$; i.p.). On the following day, all animals were anesthetized by diethyl ether (by inhalation), and the blood was collected for analysis of serum total cholesterol (TC) and triglycerides (TGs).

Effect on high fat diet-induced hypercholesterolemia. The effect of OM on high fat diet-induced hypercholesterolemia was studied using the method described by Berroughui et al. ${ }^{13}$ with slight modifications introduced after pilot studies. Adult SD rats (12-14 weeks old, weighing 140-160 g) were randomly divided into three groups (7-10 in each). Group 1 was fed diet A (served as normal control), group 2 was fed diet $C$ (atherogenic control) and group 3 was fed diet D (treated). Animals in all groups had free access to water and food. Diet consumption was monitored daily, and the gain in body weight was monitored weekly. At the end of 6 weeks of treatment, animals were fasted for $16 \mathrm{~h}$ before blood collection, and samples were analyzed for serum lipids and glucose levels.

Free radical scavenging activity. The method reported by Blois ${ }^{14}$ was followed with a slight modification. A $0.1 \mathrm{~mm}$ solution of 1,1-diphenyl-2-picryl-hydrazil (DPPH) radical in methanol was prepared, and $1 \mathrm{ml}$ of this solution was added to $3 \mathrm{ml}$ of the extract solution in methanol at different concentrations. Absorbance was measured after $30 \mathrm{~min}$ at $517 \mathrm{~nm}$ using a Beckman DU-70 Spectrophotometer (Beckman Instruments, Fullerton, CA, USA). A decrease in the absorbance of DPPH solution indicates an increase in DPPH radical scavenging activity. The percentage of the radical scavenging activity of DPHH was calculated by the equation:

$\%$ DPPH radical scavenging $=$

$$
\left(1-\frac{\text { Control Absorbance }- \text { Sample Absorbance }}{\text { Control Absorbance }}\right) \times 100
$$

The DPPH solution was used as the control. The CRCs were plotted as concentration of extracts in $\mu \mathrm{g} \mathrm{ml}^{-1}$ against the percentage of free radical scavenging activity for the calculation of $\mathrm{EC}_{50}$ values along with the $95 \%$ confidence interval $(95 \% \mathrm{CI})$.

Estimation of lipid profiles and glucose levels. Blood was collected in a vacutainer by cardiac puncture from anesthetized rats that were fasted overnight. The serum was separated after centrifugation at 3000 r.p.m./Eppendorf Centrifuge 5418 for $10 \mathrm{~min}$. Serum lipids and glucose were assayed enzymatically using commercially available kits. Serum TC, high-density lipoproteincholesterol (HDL-C), TG and glucose levels were determined using methods described by the manufacturer (Randox Laboratories). Low-density lipoprotein-cholesterol (LDL-C) was estimated indirectly using the formula: $\mathrm{LDL}=\mathrm{TC}-\mathrm{HDL}-\mathrm{TG} / 5 .{ }^{15}$ The atherogenic index was calculated using the formula: atherogenic index $=\mathrm{TC}-\mathrm{HDL} / \mathrm{HDL}$.

\section{Safety assessment}

Orchis mascula was evaluated for acute toxicity. Balb-C mice were divided into four groups of six and were administered increasing doses of the OM crude extract $\left(1,2\right.$ and $\left.3 \mathrm{~g} \mathrm{~kg}^{-1}\right)$ in a $10 \mathrm{ml} \mathrm{kg}^{-1}$ volume. A negative control group of mice was administered saline $\left(10 \mathrm{ml} \mathrm{kg}^{-1}\right.$, per oral (p.o.)). The mice were kept under observation for mortality and behavioral changes for $48 \mathrm{~h}$ and allowed food and water ad libitum during this time.

\section{Statistical analysis}

All data were expressed as means \pm s.e.m., and the median $\mathrm{EC}_{50}$ values were calculated as the geometric mean with $95 \%$ CIs. CRCs were analyzed by nonlinear regression. One-way analysis of variance (one-way ANOVA) followed by Tukey's post-test was used to determine significant differences in various biological parameters with and without treatment. Two-way ANOVA followed by Bonferroni's post-test correction was used for multiple comparisons of CRCs with control. $P$-values $<0.05(P<0.05)$ were considered statistically significant. All the graphing, calculations and statistical analyses were performed using GraphPad Prism software version 4.00 for Windows, (GraphPad Software, San Diego, CA, USA, http://www.graphpad.com).

\section{RESULTS}

\section{Phytochemical screening}

Qualitative phytochemical screening of the crude extract of ground powder of OM (Om.Cr) showed the presence of alkaloids, saponins, tannins, phenolics, terpenes, sterols and flavonoids.

\section{Effects on BP and lipid profile in SHRs}

The treatment of SHRs with OM for 8 weeks significantly reduced elevated systolic BP $(P<0.05)$, along with serum TGs, LDL-C and atherogenic index compared with untreated controls. No effects were observed on TC, HDL-C and glucose (Table 1). Treatment also

Table 1 Effects of Orchis mascula (OM) on blood pressure, serum lipids and glucose in SHR

\begin{tabular}{|c|c|c|c|}
\hline Parameters & $W K Y$ & $S H R$ & SHR+Orchis mascula \\
\hline Systolic BP (mm Hg) & $140.7 \pm 3.4$ & $203.4 \pm 7.13^{\dagger \dagger}$ & $174.2 \pm 9.63^{*}$ \\
\hline Heart rate (b.p.m.) & $322.1 \pm 11.7$ & $331.3 \pm 6.02$ & $333.3 \pm 8.28$ \\
\hline Total cholesterol (mg per $100 \mathrm{ml}$ ) & $110.9 \pm 7.8$ & $90.3 \pm 7.7$ & $69.51 \pm 11.62$ \\
\hline HDL-C (mg per $100 \mathrm{ml}$ ) & $93.9 \pm 6.6$ & $68.3 \pm 7.1^{\dagger}$ & $63.51 \pm 10.75$ \\
\hline LDL-C (mg per $100 \mathrm{ml})$ & $17 \pm 3.6$ & $21.9 \pm 3.5$ & $5.99 \pm 1.27^{*}$ \\
\hline Triglycerides (mg per $100 \mathrm{ml}$ ) & $80.42 \pm 4.0$ & $93.84 \pm 5.7^{\dagger}$ & $29.28 \pm 6.99 * *$ \\
\hline Atherogenic index & $0.183 \pm 0.04$ & $0.36 \pm 0.08^{\dagger \dagger}$ & $0.096 \pm 0.017^{*}$ \\
\hline Glucose (mg per $100 \mathrm{ml}$ ) & $116 \pm 8.9$ & $89.6 \pm 12.0$ & $97.78 \pm 23.74$ \\
\hline
\end{tabular}

Abbreviations: ANOVA, analysis of variance; BP, blood pressure; b.p.m., beats per minute; HDL-C, high-density lipoprotein cholesterol; LDL-C, low-density lipoprotein cholesterol; SHR, spontaneously hypertensive rat; WKY, Wistar Koyoto.

One-way ANOVA followed by Tukey's post-test. WKY rats served as normotensive controls.

Values shown are mean \pm s.e.m. of $7-10$ determinations

${ }^{*} P<0.05 ;{ }^{* *} P<0.001$ compared with SHR control.

$\uparrow P<0.05 ; \uparrow P<0.01$ compared with normotensive WKY control. 


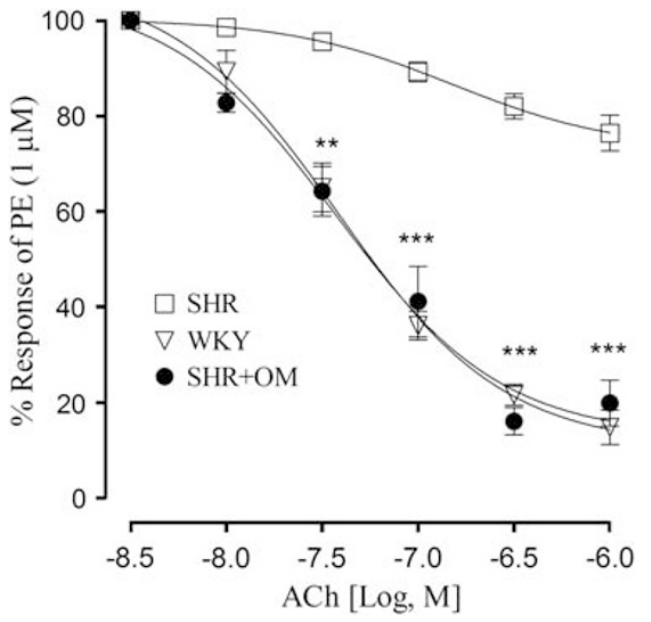

Figure 1 Concentration-response curves showing the comparative vasorelaxant effects of acetylcholine (ACh) on phenylephrine (PE; $1 \mu \mathrm{m}$ ) induced vasoconstriction in aortae isolated from SHRs (hypertensive control), SHRs treated with 3\% OM for two months (SHR+OM) and Wistar Koyoto rats (WKY, normotensive control). The symbols represent the means \pm s.e.m. of $5-10$ preparations. $\left({ }^{* *} P<0.01,{ }^{* *} P<0.001\right.$; compared with untreated SHRs; two-way ANOVA followed by Bonferroni's post-test correction).

improved the endothelial-dependent relaxation of PE-induced contractions in isolated aortae compared with those of untreated controls. The comparative concentration curves of $\mathrm{ACh}$ in the aortae of different groups are presented in Figure 1.

\section{Effects on BP in normotensive anesthetized rats}

The crude extract of OM (Om.Cr) caused a dose-dependent (10 and $30 \mathrm{mg} \mathrm{kg}^{-1}$ ) decrease in the BP of normotensive anesthetized rats. The doses of 10 and $30 \mathrm{mg} \mathrm{kg}^{-1}$ induced a respective decrease of $14.5 \pm 3.5$ and $32 \pm 3 \%$ (mean \pm s.e.m.) in BP. Figure 2 (top) shows the tracing from a typical experiment, whereas the combined data obtained from different animals under the same experimental conditions have been plotted in Figure 2 (bottom).

\section{Effect on isolated rabbit aortae}

Isolated rabbit aortic ring preparations were used for the study of direct vasodilator activity and the possible mode of action(s) of OM. The crude extract of OM (Om.Cr) caused concentration-dependent (0.03-10.0 $\left.\mathrm{mg} \mathrm{ml}^{-1}\right)$ inhibition of both PE (EC ${ }_{50}, 95 \% \mathrm{CI} ; 2.6 \mathrm{mg}$ per $100 \mathrm{ml}, 1.86-3.76 ; n=5)$ and high $\mathrm{K}^{+}$-induced contractions (1.08 $\left.\mathrm{mg} \mathrm{ml}^{-1}, 0.92-1.28 ; n=5\right)$. The comparative curves are shown in Figure 3. On the endothelium of intact and denuded aortic rings of selected vascular preparation, no significant difference in the inhibitory effect of Om.Cr was found (data not shown). Om.Cr caused a concentration-dependent nonparallel rightward shift with the suppression of maximum response $(31.87 \pm 3.1$ and $57.75 \pm 6.9 \%$, $P<0.001$ vs. control) at 0.3 and $1.0 \mathrm{mg} \mathrm{m}^{-1}$, respectively, in calcium CRC (similar to those of verapamil) $(24.5 \pm 0.8$ and $61.5 \pm 3.2 \%$, $P<0.001$ vs. control) at 0.03 and $0.1 \mu \mathrm{M}$, respectively, as shown in Figure 4. Om.Cr also caused a concentration-dependent $(0.3$ and $1.0 \mathrm{mg} \mathrm{ml}^{-1}$ ) rightward shift in the $\mathrm{Ca}^{2+} \mathrm{CRCs}$ in a manner similar to that of verapamil, confirming the CCB activity (Figure 4). Furthermore, on the baseline, Om.Cr caused slight contractions at $0.3-3.0 \mathrm{mg} \mathrm{ml}^{-1}$. The contractile effect of Om.Cr was partially blocked in phentolamine $(1 \mu \mathrm{M})$ pretreated aortic rings, as shown in Figure 3. In $\mathrm{Ca}^{2+}$-free medium, PE $(1 \mu \mathrm{M})$ caused a sharp contraction because of
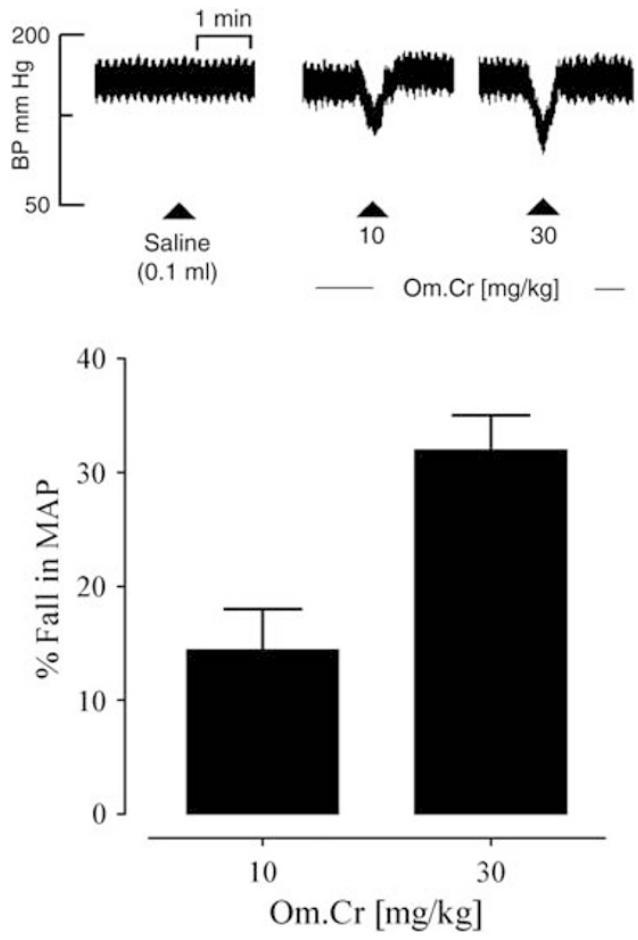

Figure 2 Typical tracing showing the blood pressure-lowering effect of the crude extract of Orchis mascula (Om.Cr) (top) and bar chart representing the hypotensive effect of Om.Cr on mean arterial pressure (MAP) in anesthetized normotensive rats (bottom). The data represent the mean \pm s.e.m. of 3 animals.
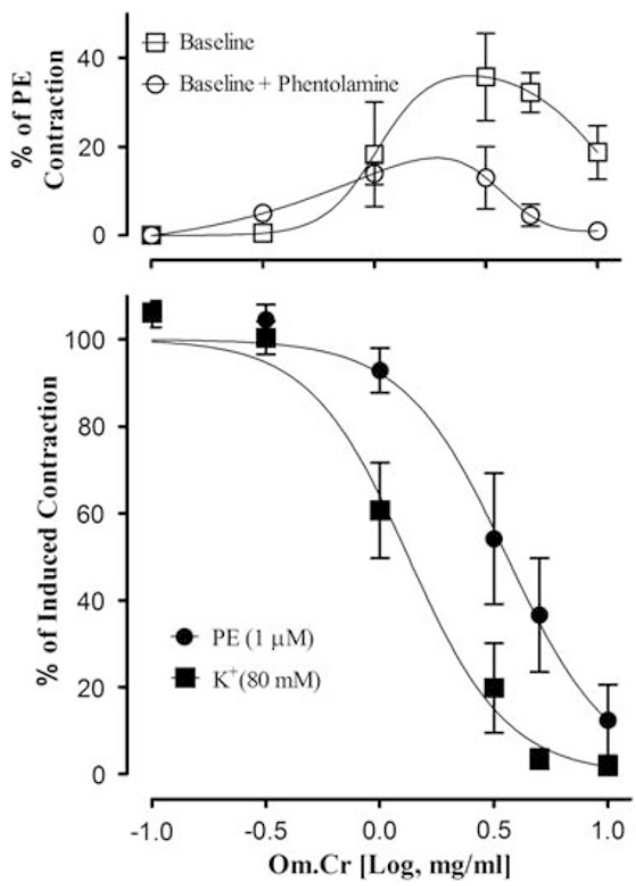

Figure 3 Effect of the crude extract of Orchis mascula (Om.Cr) on vascular contractions. The upper panel shows the effect of $\mathrm{Om} . \mathrm{Cr}$ on basal tension without and with phentolamine $(1 \mu \mathrm{m})$, in which the responses to each concentration were expressed as a percentage of the PE-induced contraction. The lower panel shows the vasodilator effect against phenylephrine (PE; $1 \mu \mathrm{m})$ and high $\mathrm{K}^{+}(80 \mathrm{~mm})$ induced contractions in isolated rabbit aortic preparations. Values shown are means \pm s.e.m. of 4-6 measurements. 
the release of $\mathrm{Ca}^{2+}$ from intracellular stores. Om.Cr also caused a reduction in these contractions in a concentration-dependent manner (0.3-3 mg per $100 \mathrm{ml}$ ), similar to that of Verapamil (data not shown).
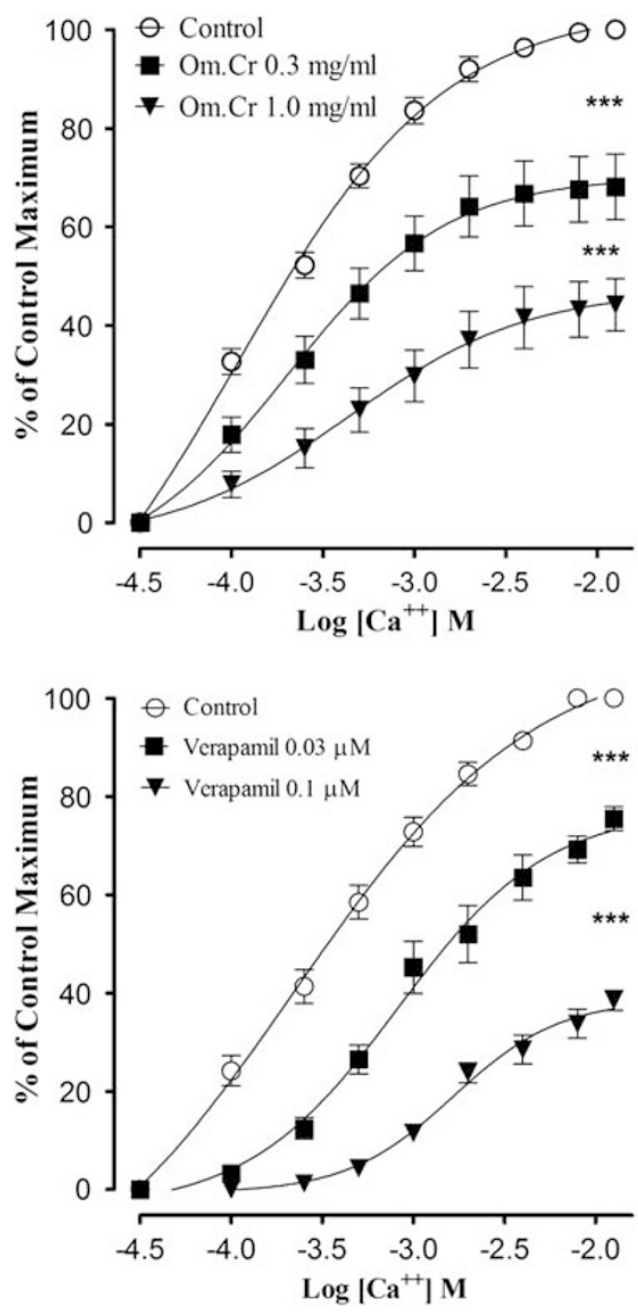

Figure 4 Effect of increasing the dose of Orchis mascula crude extract (Om.Cr) (top) and Verapamil (bottom) on $\mathrm{Ca}^{2+}$ concentration-response curves constructed in $\mathrm{Ca}^{2+}$-free and $\mathrm{K}^{+}$-rich $(80 \mathrm{~mm})$ medium in isolated rabbit aorta. Values shown are means \pm s.e.m. of $4-6$ experiments. ${ }^{* * *} P<0.001$; compared with control maximum, two-way ANOVA followed by Bonferroni's post-test correction).
Effects on tyloxapol-induced hyperlipidemia

Administration of Tyloxapol (Triton WR-1339) caused an increase in serum TC, $526.6 \pm 44.04$ vs. $82.22 \pm 3.131 \mathrm{mg}$ per $100 \mathrm{ml}(P<0.001$; $n=8-10)$, and TGs, $6276 \pm 541.6$ vs. $67.83 \pm 4.14 \mathrm{mg}$ per $100 \mathrm{ml}$ $(P<0.001 ; n=8-10)$, compared with normal controls. Pretreatment of the rats with $\mathrm{OM}$ protected partially against tyloxapol-induced hypercholesterolemia, $277.6 \pm 84.7 \mathrm{mg}$ per $100 \mathrm{ml}(P<0.05 ; n=8)$, and hypertriglyceridemia, $2823 \pm 1139 \mathrm{mg}$ per $100 \mathrm{ml}(P<0.01 ; n=8)$.

\section{Effects on high fat diet-induced hyperlipidemia}

An atherogenic diet significantly increased TC, LDL and the atherogenic index compared with controls. Supplementation of OM with an atherogenic diet prevented the increase in mean serum TC, LDL-C and the atherogenic index. The treatment did not exert any effect on HDL-C, TG and glucose levels. The decrease in body weight was accompanied by a slight reduction in daily diet consumption. The data are summarized in Table 2.

\section{In vitro antioxidant activity}

The crude extract of OM (Om.Cr). was devoid of antioxidant activity up to the maximum concentration $\left(150 \mu \mathrm{g} \mathrm{ml}^{-1}\right)$ tested by the DPPH assay.

\section{Safety assessment}

In acute toxicity studies on mice, OM crude extract (Om.Cr) up to $3 \mathrm{~g} \mathrm{~kg}^{-1}$, p.o. did not produce mortality in $48 \mathrm{~h}$ or any behavioral changes during the observation period. During chronic treatment for 6-8 weeks, OM did not cause any death or behavioral changes in normotensive and SHR rats.

\section{DISCUSSION}

In this study, chronic treatment of SHRs with OM significantly reduced systolic BP compared with untreated hypertensive controls. This may explain its medicinal use in hypertension. SHR is the most widely used animal model for human essential hypertension because of its similarities in genetic predisposition to high BP without specific etiology, increased total peripheral resistance without volume expansion, impairment of endothelial function and similar responses to drug treatment. ${ }^{16}$ The hypotensive effects of Om.Cr in normotensive anesthetized rats imply direct effects on the cardiovascular system, as $\mathrm{BP}$ is the product of cardiac output and peripheral vascular resistance ${ }^{17}$ and it effected a change in either or both of these parameters. The goal of any antihypertensive therapy is targeted to bring a reduction in either or both of these parameters, preferably peripheral vascular resistance.

Table 2 Effect of Orchis mascula (OM) on serum lipids, glucose, body weight and diet consumption in atherogenic diet

\begin{tabular}{|c|c|c|c|}
\hline Parameters & Normal diet & Atherogenic diet & Atherogenic+Orchis mascula \\
\hline Total cholesterol (mg per $100 \mathrm{ml}$ ) & $82.2 \pm 3.13$ & $356.1 \pm 18.04^{\dagger \dagger}$ & $268.6 \pm 15.28 * *$ \\
\hline HDL-C (mg per 100 ml) & $38.5 \pm 1.73$ & $27.8 \pm 3$ & $32.51 \pm 2.24$ \\
\hline LDL-C (mg per $100 \mathrm{ml}$ ) & $30.1 \pm 2.34$ & $314.52 \pm 16.6^{\dagger \dagger}$ & $183.4 \pm 38.99 * *$ \\
\hline Triglycerides (mg per 100 ml) & $59.7 \pm 4.2$ & $68.61 \pm 8.44$ & $80.18 \pm 8.94$ \\
\hline Atherogenic index & $1.15 \pm 0.09$ & $12.5 \pm 1.12^{\dagger \dagger}$ & $7.49 \pm 0.91 * *$ \\
\hline Glucose (mg per 100 ml) & $95.6 \pm 7.2$ & $147 \pm 19$ & $92.85 \pm 11.46$ \\
\hline$\%$ change in body weight & $33.33 \pm 1.6$ & $56.8 \pm 1.97^{\dagger}$ & $34.23 \pm 7.34^{*}$ \\
\hline Diet consumption g per day per kg & $168.5 \pm 11.8$ & $146.1 \pm 15.1$ & $129.2 \pm 8.6$ \\
\hline
\end{tabular}

Abbreviations: ANOVA, analysis of variance; HDL-C, high-density lipoprotein cholesterol; LDL-C, low-density lipoprotein cholesterol.

Values shown are mean \pm s.e.m. of 7-10 determinations.

$\uparrow P<0.05 ; \dagger P<0.01$ compared with normal controls.

${ }^{*} P<0.05 ;{ }^{*} P<0.01$ compared with atherogenic control. One-way ANOVA followed by Tukey's post-test. 
Vascular resistance is regulated by the endothelium through the synthesis and secretion of various vasoactive substances. In SHR, vascular endothelial dysfunction is caused by various factors, such as hypertension, ${ }^{18}$ hypertriglyceridemia ${ }^{19}$ and the excess production of oxidants and/or deficiency of antioxidant systems. ${ }^{20}$ Treatment of SHR with OM completely reversed endothelial dysfunction (indicated by increased vasorelaxation induced by $\mathrm{ACh}$ ) comparable with WKY normotensive controls, and this effect was associated with a reduction in serum TGs, LDL-C and the atherogenic index. All of these are independent risk factors in the development of endothelial dysfunction.

Blood pressure is the product of cardiac output and peripheral vascular resistance. An increase in either or both of these results in hypertension. The ability of Om.Cr to relax the contractions induced by $\mathrm{PE}$ and high $\mathrm{K}^{+}$in isolated rabbit aorta is indicative of the blockade of $\mathrm{Ca}^{2+}$ influx through both receptor-operated and L-type voltagedependent $\mathrm{Ca}^{2+}$ channels, respectively. ${ }^{21} \mathrm{The} \mathrm{Ca}^{2+}$ channel blockade (CCB) activity of Om.Cr was further confirmed by the rightward shift of $\mathrm{Ca}^{2+} \mathrm{CRCs}$ with the suppression of maximum response $(P<0.001$ vs. control), caused by Om.Cr, similar to the effects of verapamil, a standard CCB used clinically. ${ }^{22}$ The beneficial effects of CCBs are due to multiple mechanisms, such as a direct relaxant effect on the cardiovascular system by blocking the entry of $\mathrm{Ca}^{2+}$ into the cells, an antidyslipidemic effect due to an increase in cholesteryl ester hydrolysis by increasing intracellular cyclic adenosine monophosphate and inherent antioxidant properties. ${ }^{23} \mathrm{In} \mathrm{Ca}^{2+}$-free Kreb's solution, PE acts through stimulation of $\alpha_{1}$-adrenergic receptors followed by the conversion of phosphatidylinositol to inositol-1,4,5-trisphosphate, which in turn releases $\mathrm{Ca}^{2+}$ from the intracellular stores and brings about the contraction. ${ }^{24-25}$ In a normal $\mathrm{Ca}^{2+}$ Kreb's solution, the PEstimulated contractions come about possibly through the influx of $\mathrm{Ca}^{2+}$ from the L-type voltage-dependent $\mathrm{Ca}^{2+}$ channels and the receptor-operated nonselective cation channels. ${ }^{26} \mathrm{Om}$.Cr appears to inhibit both mechanisms. Furthermore, the presence of vasoconstrictor constituents may also explain the partial reversal of hypertension. However, further investigations are required to verify this.

To study the possible mode of action of the lipid-lowering activity of OM, tyloxapol and the high cholesterol diet-induced hyperlipidemia models were used. In tyloxapol-induced hyperlipidemia, OM caused a significant reduction in both serum TG and TC levels to levels comparable with controls. Tyloxapol caused an increase in serum TGs and cholesterol levels because of the increase in hepatic cholesterol synthesis, particularly by the increase in HMG Co-A activity $^{27}$ and by the inhibition of lipoprotein lipase (LPL) responsible for hydrolysis of plasma lipids. ${ }^{28}$ This indicates the inhibition of lipid biosynthesis as a possible mechanism of the lipid-lowering effect of OM.

A high cholesterol diet induces endothelial dysfunction and atherosclerosis $^{29}$ and increases oxidative stress by increasing the expression of oxidation-sensitive genes, such as Elk-1 and p-CREB. ${ }^{30} \mathrm{~A}$ high cholesterol diet with cholic acid increases TC, LDL-C and the atherogenic index and decreases HDL-C by enhancing intestinal absorption and secretion and decreasing the catabolism of cholesterol. ${ }^{31} \mathrm{~A}$ high-fat diet also causes oxidative stress (enzymatic and nonenzymatic) in rats, as indicated by increased levels of thiobarbituric acid reactive substances and conjugated dienes, significantly attenuated activities of superoxide dismutase, catalase, glutathione peroxidase and glutathione-S-transferase, as well as reduced glutathione levels in the liver, heart, kidney, intestine and aorta. Antioxidants effectively prevent this kind of cellular damage. ${ }^{32}$ The reduction of serum TC, LDL-C and the atherogenic index indicates that OM reduces intestinal absorption and secretion and also possesses in vivo antioxidant activity. However, Om.Cr did not show in vitro antioxidant activity in the DPPH free radical scavenging assay. The presence of in vivo antioxidant activity of OM may prevent the disturbance in $\mathrm{Ca}^{2+}$ homeostasis, which is essential for the synthesis and release of nitric oxide from endothelial cells. ${ }^{33}$ Furthermore, the reduction of body weight gain by $\mathrm{OM}$ may be due to the reduction in daily diet consumption, which may be useful in CVD associated with obesity. The phytochemical screening indicated the presence of phenolic acids, terpenes, flavonols and tannins, which are known antioxidants. Owing to the multifaceted nature of antioxidants, it may not be possible to rule out the presence of in vitro antioxidant activity in OM on the basis of a single assay. ${ }^{34}$ Therefore, other methods such as reactive oxygen species scavenging assays and electron transferbased assays should be attempted. Moreover, antioxidation is not the sole mechanism of the lipid-lowering activity of OM.

\section{CONCLUSIONS}

Antihypertensive and endothelial modulating effects of $\mathrm{OM}$ are mediated through multiple pathways that include a direct vasorelaxant effect through CCB and the inhibition of both lipid biosynthesis and intestinal absorption and secretion. This study rationalizes the medicinal use of OM in hypertension and dyslipidemia. However, further studies are required to isolate and identify active constituent(s) of OM responsible for its beneficial medicinal effects.

\section{ACKNOWLEDGEMENTS}

This study was supported by the Pakistan Science Foundation through research grant PSF/R\&D/S-AKU/Bio (377).

1 Usmanghani K, Saeed A, Alam MT. Indusyunic Medicine: Traditional Medicine of Herbal, Animal and Mineral Origin in Pakistan. B.C.C. and T. Press, University of Karachi: Karachi, 1997, pp 320-321.

2 Aziz N, Mehmood MH, Mandukhail SR, Bashir S, Raoof S, Gilani AH. Antihypertensive, antioxidant, antidyslipidemic and endothelial modulating activities of a polyherbal formulation (POL-10). Vascul Pharmacol 2009; 50: 56-64.

3 Williamson EM, Okpako DT, Evans FJ. Pharmacological Methods in Phytotherapy Research. John Wiley \& Sons: Chichester, 1998, pp 15-23.

4 National Research Council. Guide for the Care and Use of Laboratory Animals. National Academy Press: Washington, 1996, pp 1-7.

5 Tona L, Kambu K, Ngimbi N, Cimanga K, Vlietinck AJ. Antiamoebic and phytochemical screening of some Congolese medicinal plants. J Ethnopharmacol 1998; 6: 57-65.

6 Harkness JE, Wagner JE. The Biology and Medicine of Rabbits and Rodents, 4th edn. Williams and Wilkins: Hagerstown, 1995.

7 Ichihashi T, Izawa M, Miyata K, Mizui T, Hirano K, Takagishi Y. Mechanism of hypocholesterolemic action of S-8921 in rats: S-8921 inhibits ileal bile acid absorption. J Pharmacol Exp Ther 1998; 284: 43-50.

8 Rodrigo E, Maeso R, Munoz-Gracia R, Navaroo-Cid J, Ruilope LM, Cachofeiro V, Lahera $\mathrm{V}$. Endothelial dysfunction in spontaneously hypertensive rats: consequences of chronic treatment with losartan or captopril. J Hypertens 1997; 15: 613-618.

9 Gilani AH, Jabeen Q, Ghayur MN, Janbaz KH, Akhtar MS. Studies on the antihypertensive, antispasmodic, bronchodilator and hepatoprotective activities of the Carum copticum seed extract. J Ethnopharmacol 2005; 98: 127-135.

10 Furchgott RF, Zawadski JV. The obligatory role of endothelial cells in the relaxation of arterial smooth muscle by acetylcholine. Nature 1980; 299: 373-376.

11 Guan YY, Kwan CY, Daniel EE. The effects of EGTA on vascular smooth muscle contractility in calcium free medium. Can J Physiol Pharmacol 1988; 66: 1053-1056.

12 Khanna AK, Rizvi F, Chander R. Lipid lowering activity of Phyllanthus niruri in hyperlipemic rats. J Ethnopharmacol 2002; 82: 19-22.

13 Berroughui H, Ettaib A, Herrera Gonzalez MD, Alvarez de Sotomayor M, Bennari-Kabchi $\mathrm{N}$, Hmamouchi M. Hypolipidemic and hypocholesterolemic effect of argan oil (Argania spinosa L.) in Meriones Shawi rats. J Ethnopharmacol 2003; 89: 15-18.

14 Blois MS. Antioxidant determinations by the use of a stable free radical. Nature 1958; 26: 1199-1200.

15 Friedwald WT, Levy R L, Fredrickson DS. Estimation of the concentration of low density lipoprotein cholesterol in plasma without use of the preparative ultracentrifuge. Clin Chem 1972; 18: 499. 
16 Mulvany MJ, Halpern W. Contractile properties of small arterial resistance vessels in spontaneously hypertensive and normotensive rats. Circ Res 1977; 41: 19-26.

17 Johansen PL. Hemodynamic effects of calcium antagonists in hypertension. In Epstein M. (ed). Calcium Antagonists in Clinical Medicine. Hanley and Belfus Inc: Philadelphia, 1992, pp 69-88.

18 Vanhoutte PM, Boulanger CM. Endothelium-dependent responses in hypertension. Hypertens Res 1995; 18: 87-98.

19 Bartus M, Lomnicka M, Lorkowska B, Franczyk M, Kostogrys RB, Pisulewski PM, Chlopicki S. Hypertriglyceridemia but not hypercholesterolemia induces endothelial dysfunction in the rat. Pharmacol Rep 2005; 57(Suppl): 127-137.

20 Akpaffiong MJ, Taylor AA. Antihypertensive and vasodilator actions of antioxidants in spontaneously hypertensive rats. Am J Hypertens 1998; 11: 1450-1460.

21 Karaki H, Ozaki H, Hori M, Mitsui-Saito M, Amano K, Harada K, Miyamoto S, Nakazawa $\mathrm{H}$, Won KJ, Sato K. Calcium movements, distribution, and functions in smooth muscle. Pharmacol Rev 1997; 49: 157-230.

22 Godfraind T, Miller R, Wibo M. Calcium antagonism and calcium entry blockade. Pharmacol Rev 1986; 38: 312-416.

23 Etingin OR, Hajjar DP. Calcium channel blockers enhance cholesteryl ester hydrolysis and decrease total cholesterol accumulation in human aortic tissue. Circ Res 1990; 66: $185-190$.

24 Cauvin C, Malik S. Induction of calcium influx and calcium release in isolated rat aorta and mesenteric resistance vessels by norepinephrine activation of $\alpha$-receptors. J Pharmacol Exp Ther 1984; 230: 413-418.

25 Hashimoto M, Hirata M, Itoh T, Kanmura Y, Kuriyama H. Inositol 1, 4, 5-triphosphate activates pharmaco-mechanical coupling in smooth muscle of rabbit mesenteric artery. J Physiol 1986; 370: 605-618.
26 Karaki H. Inhibitory effects of calcium channel blockers in vascular smooth muscle. In Proceedings of the Asia-Pacific Symposium on Ca-Antagonists, Tokyo. Churchill Livingstone: New York, 1993, pp 3-11.

27 Kuroda M, Tanzawa K, Tsujita Y, Endo A. Mechanism for elevation of hepatic cholesterol synthesis and serum cholesterol levels in Triton WR-1339-induced hyperlipidemia. Biochim Biophys Acta 1977; 489: 119-125.

28 Schotz MC, Scanu A, Page IH. Effect of Triton on lipoprotein lipase of rat plasma. Am J Physiol 1957; 188: 399-402.

29 Hayashi T, Ishikawa T, Naito M, Kuzuya M, Funaki C, Asai K, Kuzuya F. Low level hyperlipidemia impairs endothelium-dependent relaxation of porcine coronary arteries by two mechanisms. Functional change in endothelium and impairment of endothelium-dependent relaxation by two mediators. Atherosclerosis 1991; 87: 23-38.

30 de Nigris F, Lerman A, Ignarro LJ, Williams-Ignarro S, Sica V, Baker AH, Lerman LO, Geng YJ, Napoli C. Oxidation-sensitive mechanisms, vascular apoptosis and atherosclerosis. Trends Mol Med 2003; 9: 351-359.

31 Heuman DM, Vlahcevic ZR, Bailey ML, Hylemon PB. Regulation of bile acid synthesis II. Effect of bile acid feeding on enzymes regulating hepatic cholesterol and bile acid synthesis in the rat. Hepatology 1988; 8: 892-897.

32 Vijayakumar RS, Surya D, Nalini N. Antioxidant efficacy of black pepper (Piper nigrum L.) and piperine in rats with high fat diet induced oxidative stress. Redox Report 2004; 9: 105-110.

33 Pogan L, Garneau L, Bissonnette P, Wu L, Sauve R. Abnormal $\mathrm{Ca}^{2+}$ signalling in vascular endothelial cells from spontaneously hypertensive rats: role of free radicals. J Hypertens 2001; 19: 721-730.

34 Huang D, Ou B, Prior RL. The chemistry behind antioxidant capacity assays. J Agric Food Chem 2005; 53: 1841-1856. 